\title{
Determination of fluoroquinolone antibiotics in hospital and municipal wastewaters in Coimbra by liquid chromatography with a monolithic column and fluorescence detection
}

\author{
M. Seifrtová • A. Pena • C. M. Lino • P. Solich
}

Received: 31 October 2007 /Revised: 18 February 2008 / Accepted: 22 February 2008 / Published online: 20 April 2008

(C) Springer-Verlag 2008

\begin{abstract}
The main goal of this work was determination of residues of the antibiotics ofloxacin (OFLO), norfloxacin (NOR), ciprofloxacin (CIPRO), and enrofloxacin (ENRO) in wastewater samples. The samples, after acidification to $\mathrm{pH} 4.5$ and addition of EDTA, were extracted on an anion-exchange cartridge in tandem with an Oasis HLB cartridge. The LC-FD method, developed in previous studies, was based on application of a monolithic $\mathrm{C}_{18}$ column. The limit of quantification (LOQ) of the method was $250 \mathrm{ng} \mathrm{L}^{-1}$ for OFLO, $25 \mathrm{ng} \mathrm{L}^{-1}$ for NOR and CIPRO, and $50 \mathrm{ng} \mathrm{\textrm {L } ^ { - 1 }}$ for ENRO. Mean recovery ranged between 75 and $121 \%$ for OFLO, NOR, CIPRO, and ENRO. A total of 14 wastewater samples were analyzed; these were collected from four hospitals and from influent and effluent from a wastewatertreatment plant in Coimbra, Portugal, during spring and autumn. CIPRO was present in all the samples, NOR was detected second most often, followed by OFLO. ENRO was found at concentrations under the LOQ in five hospital samples, and the highest level was found in influent from the WWTP.
\end{abstract}

Keywords Fluoroquinolones - LC · Monolithic column · Pharmaceuticals $\cdot$ Hospital and municipal wastewater

M. Seifrtová $\cdot$ P. Solich

Department of Analytical Chemistry,

Faculty of Pharmacy, Charles University,

Heyrovského 1203,

50005 Hradec Králové, Czech Republic

A. Pena $(\bowtie) \cdot$ C. M. Lino

Group of Bromatology,

Center of Pharmaceutical Studies,

University of Coimbra,

3000 Coimbra, Portugal

e-mail: apena@ci.uc.pt

\section{Introduction}

Pharmaceuticals are emerging environmental contaminants that have caused increased concern in recent years, because studies have indicated the presence of antibiotics in hospital and municipal wastewaters [1] that may enter aquatic systems. Antibiotics residues have been found in a wide range of environmental samples, including surface water, ground water, and drinking water [5]. The selection and development of antibiotic-resistant bacteria is one of the greatest concerns regarding the use of antibiotics [6].

Despite the large quantities used, published data on the amounts and patterns of use of antibiotics are scarce. Generally, fluoroquinolones (FQ) are prescribed in human medicine between 300-600 mg per day for therapeutic treatment of the patient. They are almost all excreted as unchanged compounds in the urine and are, consequently, discharged into hospital sewage or municipal wastewater [7]. Hospital wastewater is one of the main sources of contamination. Antibiotic concentrations calculated and measured in hospital effluents are of the same order of magnitude as minimum inhibitory concentrations for susceptible pathogenic bacteria [8]. Depending on treatment of the sewage water, different concentrations of the active compounds are found after treatment and are transported into aquatic systems $[5,9,10,11]$. In recent years, several initiatives have been launched to establish or strengthen surveillance systems, both in EC member states and at an international level, to monitor the presence of antibiotic residues in environmental waters; these have revealed levels of antibiotic residues in this type of sample.

Several analytical methods have been developed to extract, concentrate, and quantify FQ residues in environmental water samples. There are reports of use of solid-phase extraction (SPE), for extraction and concentration of FQ, and analysis by 
liquid chromatography (LC) with fluorescence detection (FD) $[11,12]$ ultraviolet detection (UV) [13], and mass spectrometric (MS) [14] or tandem mass spectrometric (MS-MS) detection [15].

This paper describes the development and validation of analytical methodology for specific and sensitive determination of the FQ antibiotics ofloxacin (OFLO), norfloxacin (NOR), ciprofloxacin (CIPRO), and enrofloxacin (ENRO), in hospital and municipal wastewaters. The methodology is based on tandem SPE (SAX and Oasis HLB cartridges) and sensitive LC-FD analysis, using a Chromolith RP-18e monolithic column [16]. Our work focussed on estimation of the presence of the compounds in four hospital wastewaters, because these are an important route of entry of human-use antibiotics into the environment, and into influents and effluents of a municipal wastewater treatment plant (WWTP) in Coimbra, Portugal. Because WWTPs are considered to be point sources of antibiotic contamination of surface and ground waters, it is very important to predict the concentration of these antibiotics and to evaluate the efficiency of the treatment. Some preliminary results from field measurements are reported.

\section{Experimental}

\section{Reagents}

Standards of OFLO, NOR, CIPRO and ENRO were purchased from Sigma-Aldrich (Steinheim, Germany). These FQ were $>98 \%$ purity. LC-grade methanol was supplied by Carlo Erba (Milan, Italy), phosphoric acid RPE-ACS by Carlo Erba (Milan, Italy), sulfuric acid 95-97\% Reagente "Baker Analyzed" by Baker (Deventer, The Netherlands), tetrabutylammonium hydroxide (TBA) by Sigma-Aldrich, and EDTA by Merck (Germany). Water was HPLC grade. The cartridges used for SPE were Oasis HLB 6 cc/200 mg (Waters, Milford, MA, USA) and AccuBOND II SAX Cartridges $6 \mathrm{~mL} / 500 \mathrm{mg}$ (Agilent Technologies, Santa Clara, USA).

Apparatus and chromatographic conditions

The LC method described here was performed with one pump (model 307, Gilson Medical Electronics, France), a Model 7125 injector (Rheodyne, Cotati, California, USA), and a Perkin-Elmer (Beaconsfield, UK) model LS45 spectrofluorimeter operated at an excitation wavelength of $278 \mathrm{~nm}$ and an emission wavelength of $450 \mathrm{~nm}$. The spectral bandwidth was $10 \mathrm{~nm}$ for both excitation and emission. The results were recorded by FL WinLab Software and a 3390A integrator (Perkin-Elmer). The four FQ were eluted isocratically $0.025 \mathrm{~mol} \mathrm{~L}^{-1}$ phosphoric acid solution (pH adjusted to 3.0 with TBA-methanol-acetonitrile 920:70:10 $(v / v)$ as mobile phase. Analysis was performed on a monolithic column (Chromolith Performance RP-18e; $100 \times 4.6 \mathrm{~mm}$ ) at a flow rate of $1.2 \mathrm{~mL} \mathrm{~min}^{-1}$ and at room temperature.

Sample collection and preparation

A total of fourteen 24-h composite wastewater samples from the four hospitals situated in Coimbra and from the influents and effluents of the local wastewater-treatment plant, were collected during the spring and autumn of 2007. Wastewater samples were collected in amber glass bottles and kept in a cooler with ice during transportation. After delivery to the laboratory, samples were filtered through $0.45-\mu \mathrm{m}$ glass fibre filters, to remove suspended matter, and stored in the dark at $4^{\circ} \mathrm{C}$ until extraction, which occurred within two days.

\section{Standard fluoroquinolone solutions}

Individual stock standard solutions $\left(1 \mathrm{mg} \mathrm{mL}^{-1}\right)$ were prepared in $0.005 \mathrm{~mol} \mathrm{~L}^{-1}$ sulfuric acid. The working standard solutions were a mixture of the four compounds prepared by appropriate dilution of the stock solutions with $0.005 \mathrm{~mol} \mathrm{~L}^{-1}$ sulfuric acid.

\section{Extraction and clean-up}

Prior to extraction, wastewater samples were filtered through $0.2 \mu \mathrm{m}$ membrane filters. After acidification to $\mathrm{pH} 4.5$ and addition of EDTA, they were extracted through an anion-exchange cartridge in tandem with an Oasis HLB cartridge. The cartridges were previously pre-conditioned with $2 \mathrm{~mL}$ methanol followed by $2 \mathrm{~mL}$ of citric acid $(\mathrm{pH}$ 4.0). The samples were percolated at a flow rate of approximately $3 \mathrm{~mL} \mathrm{~min}{ }^{-1}$. After sample percolation, the cartridges were dried for a while and then the SAX cartridge was removed and the washing step was performed with the Oasis HLB cartridge only. The cartridge was washed with $2 \mathrm{~mL}$ citric acid (pH 4.0) and $20 \mathrm{~mL}$ Milli-Q water at $\mathrm{pH}$ 4.2. Afterwards, they were vacuum dried for $15 \mathrm{~min}$. Subsequently, the analytes were eluted with $4 \mathrm{~mL}$ methanol.

Clean-up efficiencies were studied to monitor the effect of $\mathrm{pH}$ on retention of the $\mathrm{FQ}$, the effects of the solvents and $\mathrm{pH}$ used in the preconditioning and washing steps, and the effects of the nature and volume of the eluent solvents.

Before injection into the chromatographic system, the methanolic eluate was concentrated to dryness under a gentle stream of nitrogen, redissolved in mobile phase, and filtered through a $0.45-\mu \mathrm{m}$ membrane filter. 


\section{Results and discussion}

Optimization of HPLC conditions

Our previous experiments showed that with Chromolith column the best result in terms of resolution and selectivity were achieved at $\mathrm{pH} 3.0$ in the presence of TBA [16], which is in accordance with the results of Forlay-Frick and Fekete [17]. A Chromolith Performance RP-18e column $(100 \times 4.6 \mathrm{~mm})$ was used with a $10-\mathrm{mm}$ precolumn, at room temperature; separation was accomplished in 12 min with an isocratic mobile phase - a 920:70:10 ( $v / v)$ mixture of phosphoric acid adjusted to $\mathrm{pH} 3.0$ with tetrabutylamonium hydroxide (TBA), methanol, and acetonitrile, at a flow rate of $1.2 \mathrm{~mL} \mathrm{~min}^{-1}$.

On the basis of three parallel determinations, on three days, the mean retention times and relative standard deviation (RSD, \%) for OFLO, NOR, CIPRO, and ENRO were $4.47,6.50,7.59$, and $10.70 \mathrm{~min}$, and $0.52 \%, 0.39 \%$, $0.40 \%$, and $1.17 \%$, respectively.

Excitation-emission scans were performed to establish optimum excitation and emission wavelengths. The maximum wavelengths obtained for the different fluoroquinolones were: for OFLO $\lambda_{\text {ex }} 277 \mathrm{~nm}, \lambda_{\mathrm{em}} 490 \mathrm{~nm}$, for NOR $\lambda_{\text {ex }} 280 \mathrm{~nm}, \lambda_{\text {em }} 447 \mathrm{~nm}$, for CIPRO $\lambda_{\text {ex }} 279 \mathrm{~nm}, \lambda_{\text {em }}$ $445 \mathrm{~nm}$, and for ENRO $\lambda_{\text {ex }} 277 \mathrm{~nm}, \lambda_{\text {em }} 446 \mathrm{~nm}$. Chromatographic detection was therefore performed at excitation and emission wavelengths of $278 \mathrm{~nm}$ and $450 \mathrm{~nm}$, respectively.

A previous interference study showed that the solvent used to prepare standard solutions of OFLO, NOR, CIPRO, and ENRO has no effect in fluorescence intensity [16].

\section{Optimization of extraction and clean-up}

Acidification of the sample with a weak acid (acetic acid) at $\mathrm{pH} 4.5$ was selected because the FQ, with a piperazinyl moiety, are fully protonated at low $\mathrm{pH}$. EDTA was added as chelating reagent, because the FQ form stable complexes with $\mathrm{Ca}$ (II), $\mathrm{Mg}$ (II), and $\mathrm{Al}$ (III) by ion-dipole interaction with the 4-keto oxygen and the ionized 3-carboxylic acid groups [18].

The cleanup efficiencies were studied to monitor the effects of the type of cleanup cartridge, the solvents used in the preconditioning and washing steps, the solvents used for elution, and the volumes for eluting FQ from the cartridges. When Oasis HLB cartridges (poly(divinylbenzene-co- $N$ pyrrolidone) were used in the Pena et al. [16] method for determination of $\mathrm{FQ}$ residues in surface waters some interferences were observed at the retention times of the FQ. Under our experimental conditions, this cleanup was not efficient in removing the interferences from this type of water sample.
As reported by other authors [12-14, 19], our findings showed that a more effective cleanup procedure that can separate FQ from impurities present in wastewater samples is essential. Turiel et al. [20] also observed that a single cleanup through a $\mathrm{C}_{18}$ cartridge was not always sufficient for analysis of FQ residues in this type of matrix. Recently, tandem SPE methods using a strong anion-exchange (SAX) cartridge and an HBL cartridge were studied for soil and pig slurry samples [21]. Organic matter reduces extraction efficiency and can interfere with detection [22]. The anionexchange cartridges reduce matrix interferences by adsorbing negatively charged humic material and other highly negatively charged natural organic matter from the wastewater samples, thus preventing contamination, blockage, and overloading of the HLB sorbent. We applied the cleanup described by Jacobsen et al. [23] for wastewater extracts-SPE on SAX (strong anion-exchange) cartridges in tandem with Oasis HLB cartridges.

At $\mathrm{pH} 4.5, \mathrm{FQ}$ are in the cationic form, because of deprotonation of the carboxylic acid group and protonation of the piperazinyl amino group [22], and therefore are not retained on the SAX cartridge, while the polymer Oasis HLB adsorbent with an equal ratio of hydrophilic $N$ vinylpyrrolidone and lipophilic divinylbenzene retained the FQ. They have both an acidic and basic functional groups that can interact with either hydrophilic or lipophilic portion, of the Oasis HLB adsorbent [24].

Because of the acid-base properties of the FQ, SPE of the analytes is expected to be strongly dependent on $\mathrm{pH}$. During this optimization stage, different buffers for cartridge conditioning and different sample $\mathrm{pH}$ were evaluated. Samples were evaluated at $\mathrm{pH} 4.0,4.5,5.0,5.5$, and 6.0 and cartridges were conditioned with $4.38 \mathrm{mmol} \mathrm{L}^{-1}$ phosphoric acid, citric acid buffer at $\mathrm{pH} 4.7$ and 4.0, and acetate buffer at $\mathrm{pH}$ 5.5. In the Renew method [22] the cartridges were conditioned with

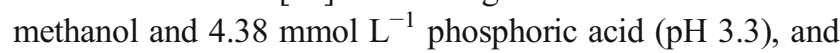
recovery ranged from 67 to $120 \%$. Under our experimental conditions, better results were obtained with the sample at pH 4.0.

When a second assay was performed with acetate buffer at $\mathrm{pH} 5.5$ the overall efficiency of recovery of FQ was: higher than $100 \%$ at $\mathrm{pH} 4.0$ and from 59 to $85 \%$ and from 55 to $84 \%$ at pH 5.0 and 5.5, respectively. According to Jacobsen et al. [23] the use of $0.04 \mathrm{~mol} \mathrm{~L}^{-1}$ citric acid buffer ( $\mathrm{pH} 4.7$ ) results in recovery higher than $100 \%$ at $\mathrm{pH}$ 4.0 and 5.0, and recovery between 60 and $86 \%$ at $\mathrm{pH} 6.0$.

Finally, citric acid buffer at $\mathrm{pH} 4.0$ was evaluated. The washing step was performed with citric acid buffer at $\mathrm{pH}$ 4.0 and water (without $\mathrm{pH}$ adjustment). Recovery values for $\mathrm{pH} 4.0,5.0$ and 5.5 varied from 82 to $148 \%$. The best recoveries, ranging from 90 to $130 \%$, were achieved for all analytes at $\mathrm{pH} 4.5$. In order to improve the washing step, citric acid buffer at $\mathrm{pH} 4.0$ and water at $\mathrm{pH} 4.2$ were used. 
The recoveries achieved for all analytes were in the range 96-114\%. Because this procedure gave the best recoveries for the FQ, it was selected and used in the analysis of wastewater samples.

After sample percolation, the Oasis cartridge was washed with $2 \mathrm{~mL} 0.04 \mathrm{~mol} \mathrm{~L}^{-1}$ citric acid buffer ( $\mathrm{pH} \mathrm{4.0)}$ and $20 \mathrm{~mL} \mathrm{H}_{2} \mathrm{O}$ at $\mathrm{pH} 4.2$, and dried under vacuum for $15 \mathrm{~min}$. FQ were eluted from the Oasis HLB cartridge with $4 \mathrm{~mL}$ methanol.

To verify the absence of interfering substances around the retention times of FQ different types of real sample were analyzed. No interference was detected in any of the samples analyzed and FQ recovery ranged between 75 and $120 \%$.

\section{Method validation}

In validation of the analytical method, the criteria sensitivity, linearity, recovery, and precision, and evaluation of matrix effects were considered.

\section{Linearity}

The calibration curves were prepared using linear regression analysis and over the established in the range gave good fits. The mean regression coefficients $\left(r^{2}\right)$ were 0.9985 for OFLO, 0.9994 for NOR, 0.9999 for CIPRO, and 0.9975 for ENRO.

\section{Stability studies}

The stability of standard solutions and of sample extracts was evaluated. Stock standard solutions were stored at $-20^{\circ} \mathrm{C}$ and analysed during a one-month period, and working standard solutions were stored at $4^{\circ} \mathrm{C}$ and analysed during a one-week period. The stability of FQ during sample storage at $-20^{\circ} \mathrm{C}$ was tested for one week; after three days, degradation of FQ working standard solutions was observed.

Limit of detection, limit of quantification, and accuracy

The limit of detection (LOD) was $85 \mathrm{ng} \mathrm{L}^{-1}$ for OFLO, $8.5 \mathrm{ng} \mathrm{L}^{-1}$ for NOR and CIPRO, and $17 \mathrm{ng} \mathrm{L}^{-1}$ for ENRO. The limit of quantification (LOQ), calculated as the lowest concentration that provides repeatabilities better than $20 \%$, was $250 \mathrm{ng} \mathrm{L}^{-1}$ for OFLO, $25 \mathrm{ng} \mathrm{L}^{-1}$ for NOR and CIPRO and $50 \mathrm{ng} \mathrm{L}^{-1}$ for ENRO.

In order to verify the absence of potential interfering substances around the retention time of $\mathrm{FQ}$, and to assess the specificity of the method, water blank samples $(n=4)$ were analyzed. No interferences were observed in the regions of interest where the FQ were eluted. These results demonstrate that real sample matrices had no effect on the performance of the proposed method, which is, therefore, suitable for analysis of trace levels of FQ in wastewaters.

The accuracy of the method was studied by spiking water samples at three fortification levels $\left(100 \mathrm{ng} \mathrm{L}^{-1}\right.$ for NOR and CIPRO, $200 \mathrm{ng} \mathrm{L}^{-1}$ for ENRO, and 1,000 $\mathrm{ng} \mathrm{L}^{-1}$ for OFLO; $200 \mathrm{ng} \mathrm{L}^{-1}$ for NOR and CIPRO, $400 \mathrm{ng} \mathrm{L}^{-1}$ for ENRO, and $2,000 \mathrm{ng} \mathrm{L}^{-1}$ for OFLO; and $500 \mathrm{ng} \mathrm{L}^{-1}$ for NOR and CIPRO, 1,000 $\mathrm{ng} \mathrm{L}^{-1}$ for ENRO, and 5,000 $\mathrm{ng} \mathrm{L}^{-1}$ for OFLO). Mean recoveries ranged between 75 and $121 \%$ for OFLO, NOR, CIPRO, and ENRO.

Within-day accuracy and precision data were determined by analysing, on the same day, three replicates of a spiked sample at three fortification levels, and one blank (to check for interferences). The between-day accuracy and precision were also determined by extracting batches of three fortification levels and analysing them on three consecutive days. For the three fortification levels, the relative standard deviation for all fortification levels on each day for each analyte was less than $10 \%$, showing good method precision.

\section{Application of method}

A total of 14 wastewaters samples collected during spring and autumn from four hospitals and from influent and effluent water from a wastewater-treatment plant (WWTP) were analysed. The measured concentrations of the FQ in the samples studied are summarized in Tables 1 and 2 . Typical chromatograms are shown in Fig. 1.

Concerning the frequency of detection, CIPRO was found, in all the samples analysed (100\%), NOR in $79 \%$, and OFLO in $50 \%$. It was not surprising that the highest concentration was for CIPRO and OFLO, which are assumed to be humaninfluence antibiotics. These results underscore the importance of development of this type of monitoring study. As mentioned above, high levels of CIPRO and OFLO, ranging from 100.8 to $10,962.5 \mathrm{ng} \mathrm{L}^{-1}$ and 353.3 to $10,675.5 \mathrm{ng} \mathrm{L}^{-1}$, respectively, were found. NOR was present at concentrations between 29.6 to $455.0 \mathrm{ng} \mathrm{L}^{-1}$. ENRO was found in WWTP influent, with a frequency of $29 \%$, ranging between 53.7 and $447.0 \mathrm{ng} \mathrm{L} \mathrm{L}^{-1}$, and was detected under the LOQ in five hospital wastewater samples.

In Germany, Hartmann et al. [2] also reported the presence of FQ in hospital wastewaters, at concentrations varying from 3 to $87 \mu \mathrm{g} \mathrm{L}^{-1}$. In Sweden [7] CIPRO was detected in the range from 3.6 to $101.0 \mu \mathrm{g} \mathrm{L}{ }^{-1}$ in hospital sewage water and in a study from the USA [5], OFLO and CIPRO were found at concentrations of 4,900-34,500 ng L $\mathrm{L}^{-1}$ and 850$2,000 \mathrm{ng} \mathrm{L}^{-1}$, respectively.

Differences were observed in wastewaters from the different hospitals. In hospitals 1 and 3, OFLO, NOR, and CIPRO were detected in both seasons. NOR and CIPRO were also found in branch 1 of hospital 4 during spring and autumn. 
Table 1 Concentrations (ng $\mathrm{L}^{-1}$ ) of $\mathrm{FQ}$ in wastewater samples collected during spring

\begin{tabular}{lclrl}
\hline Sample & OFLO & NOR & CIPRO & ENRO \\
\hline Hospital 1 & $2,289.0$ & 228.9 & $2,893.0$ & n.q. \\
Hospital 2 & $3,008.3$ & - & $1,554.5$ & - \\
Hospital 3 & 353.3 & 134.5 & $1,926.9$ & n.q. \\
Hospital 4 & & & & \\
Branch 1 & - & 29.7 & $10,962.5$ & - \\
Branch 2 & $10,675.5$ & - & $3,388.7$ & - \\
Branch 3 & - & n.q. & 127.0 & n.q. \\
Wastewater-treatment plant & & & \\
Influent & - & 191.2 & 667.1 & 447.1 \\
Effluent & - & 29.6 & 309.2 & 211.5 \\
\hline
\end{tabular}

${ }^{\mathrm{a}}$ Not quantified $(<\mathrm{LOQ})$

A seasonal influence on the frequency of detection of $\mathrm{FQ}$ in hospital wastewaters was observed, and was evident especially for OFLO, NOR, and CIPRO. Results obtained from hospitals 1 and 2, in both seasons, show comparable values of CIPRO and NOR, with the exception of OFLO. In water from hospital 2, the presence of NOR was not observed in the samples collected during spring, and OFLO was present at a higher concentration during autumn in water from hospital 1.

For hospital 3 the CIPRO level was three times higher during spring, and OFLO was approximately five times higher during the autumn.

Concerning samples from hospital 4, although it was impossible to collect samples in the three different branches in both seasons, we can state, in a general way, that for samples collected from branch 1 during spring and autumn higher concentrations of OFLO and CIPRO were found in spring.

Influent and effluent samples from WWTPs, contained NOR, CIPRO, and ENRO at lower levels than in hospital wastewater samples. These results may be explained by a dilution effect with the municipal wastewaters, or degradation processes in the aquatic environment.

Regarding the influence of season in this type of sample, we can assume that the FQ studied were detected at lower levels during the autumn season, except for NOR.

Table 2 Concentrations (ng $\mathrm{L}^{-1}$ ) of $\mathrm{FQ}$ in wastewater samples collected during autumn

\begin{tabular}{lcrrl}
\hline Sample & OFLO & NOR & CIPRO & ENRO \\
\hline Hospital 1 & $9,451.9$ & 334.0 & $2,927.2$ & - \\
Hospital 2 & $3,111.6$ & 197.3 & $1,007.3$ & n.q. $^{\text {a }}$ \\
Hospital 3 & $1,585.5$ & 88.5 & 619.9 & - \\
Hospital 4 branch 1 & - & 301.6 & 726.3 & n.q. \\
Wastewater-treatment plant & & & \\
Influent & - & 455.0 & 418.8 & 121.8 \\
Effluent & - & 35.0 & 100.8 & 53.7 \\
\hline
\end{tabular}

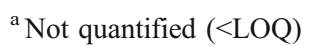

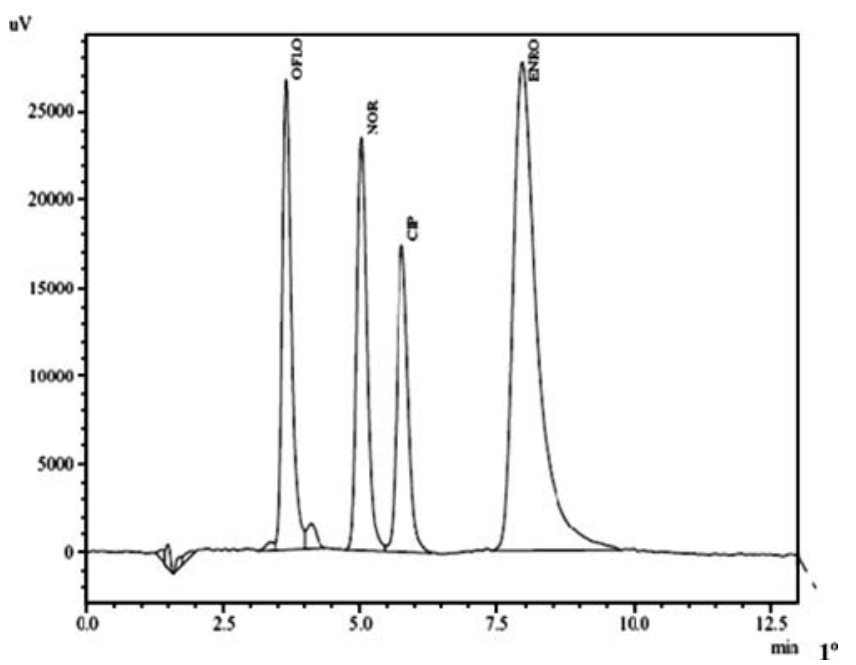

Fig. 1 Liquid chromatograms obtained from a standard solution and hospital wastewater

In the samples from the WWTPs, concentrations before and after treatment during spring were 191.2 and $29.6 \mathrm{ng} \mathrm{L}^{-1}$, 667.1 and $309.1 \mathrm{ng} \mathrm{L}^{-1}$, and 447.1 and $211.5 \mathrm{ng} \mathrm{L}^{-1}$, for NOR, CIPRO, and ENRO, respectively. For samples collected during autumn, the values were, respectively, 455.0 and $35.0 \mathrm{ng} \mathrm{L}^{-1}, 418.8$ and $100.8 \mathrm{ng} \mathrm{L}^{-1}$, and 121.8 and $53.7 \mathrm{ng} \mathrm{L}^{-1}$.

In the scientific literature $\mathrm{FQ}$ have been reported in effluents from sewage treatment plants in European countries, such as France (330-510 ng L ${ }^{-1}$ ), Italy (290-580 ng L ${ }^{-1}$ ), Greece (460 $\mathrm{ng} \mathrm{L}^{-1}$ ) [11], Switzerland (36-106 ng L ${ }^{-1}$ ) [9], (249$405 \mathrm{ng} \mathrm{L}^{-1}$ primary effluent, $45-120 \mathrm{ng} \mathrm{L}^{-1}$ tertiary effluent) [12], and also in USA (19-45 $\left.\mathrm{ng} \mathrm{L}^{-1}\right)$ [11] (110-470 $\left.\mathrm{ng} \mathrm{L}^{-1}\right)$ [15] and Canada (34-179 ng L ${ }^{-1}$ ) [19], (112-506 ng L ${ }^{-1}$ ) [25]. OFLO was detected in the effluents of WWTPs in several European countries [11], although it was not detected in our study. These different results might be due to variations in the use of FQ among countries. ENRO, used only in veterinary medicine, was detected in our study in municipal wastewaters, probably because of agricultural sources, such as manure dispersion and animal excretion on to soils.

Because CIPRO, ENRO, and OFLO have high $K_{\text {dsolid }}$ values, ranging between 496 and $61,000 \mathrm{~L} \mathrm{~kg}^{-1}$ [26], and because to their lipophilicity and tendency to form stable complexes with divalent and trivalent metal ions, they move rapidly from the water compartment into solids. Therefore, sorption to sewage sludge through hydrophobic interactions has been suggested as the main removal pathway for FQ during secondary wastewater treatment $[4,27]$ because of their immobility as a result of the high sorption coefficients for solids.

The percentage of reduction in dissolved FQ concentrations after treatment was: 85 and $92 \%$ for NOR, 54 and $76 \%$ for CIPRO, and 53 and $56 \%$ for ENRO, in spring and autumn, respectively. These results are in accordance with other 
reported studies [4]. The extent of reduction observed in our study was fairly high in autumn. However, it should be noted, that the weather was unusually warm when samples were collected during this season. This is in correlation with a study from Switzerland [9], where FQ were significantly reduced in WWTP process during the summer period than in winter.

The concentration of FQ in the final effluent from the WWTPs depends on the treatment process used. In a field study at a full-scale municipal wastewater-treatment plant in Switzerland, Golet et al. [27] determined a 49-61\% reduction in dissolved CIPRO and NOR concentrations during biological treatment, $28-35 \%$ during mechanical treatment, and about $3-4 \%$ was removed in the flocculation filtration step. They observed the combined removal during the wastewater treatment process of $88 \%$ for CIPRO and $92 \%$ for NOR. In another study of Golet et al. [12] they observed a rate of elimination during wastewater treatment between 70 and $80 \%$ after advanced treatment with contact filtration. Thus the main removal results from biological treatment.

The efficiency of antibiotics removal in WWTPs based an activated sludge process and biological nutrient removal has been evaluated [5]. Only OFLO was found in influent and effluent from WWTPs in the USA and removal efficiency was $77 \%$. FQ are known to readily sorb to sewage sludge, which may explain their higher removal rate. Lee et al. [19] observed reduction of OFLO, NOR, and CIPRO by more than $40 \%$ during the treatment process in WWTPs in Canada.

These results are in concordance with those from Switzerland where they evaluated the efficiency of the treatment process in WWTP. The reduction in concentrations if NOR and CIPRO after treatment was reported to be in the range $79-87 \%$ [9]; another study reported a reduction of $70-80 \%$ for CIPRO [13]. In Sweden [15] the efficiency reported was $87 \%$ for NOR, $86 \%$ for CIPRO, and $87 \%$ for ENRO.

CIPRO has been detected in WWTP effluents and its concentration differs according to the efficiency of treatment (22.2$100 \%$ ), which depends on the secondary treatment process used. For use of an oxidation ditch and activated sludge reduction of CIPRO was 22.2 and $71.4 \%$, respectively [10].

In a study by Renew et al. [22] they compared the efficiency of two WWTPs. Both treatment plants utilize primary and secondary (activated sludge) treatment. After this secondary treatment, one WWTP utilizes chlorination whereas the second WWTP utilizes UV disinfection. From their results they concluded levels of antibiotics were comparable after secondary treatment whereas the concentration of antibiotics differed substantially in tertiary effluents. WWTP using chlorination led to lower quantities of the antibiotics studied than the WWTP with UV disinfection.

Advanced wastewater treatment techniques, for example reverse osmosis, activated carbon, and ozonation have been shown to significantly reduce or eliminate antibiotics from wastewater effluent [5].
Therefore, more studies are necessary in order to evaluate the efficiency of the different types of treatment at local WWTPs and to avoid the entrance of antibiotic residues into the aquatic environment.

\section{Conclusions}

A method including tandem SPE (an anion-exchange cartridge and an Oasis HLB cartridge) and LC-FD analysis using a monolithic column is proposed for simultaneous determination of OFLO, NOR, CIPRO, and ENRO in hospital and municipal wastewaters.

The analytical method was found to fulfill validation requirements of linearity, accuracy, precision, and selectivity for FQ determination in wastewater samples, and may be used for routine analysis because LC-FD is an inexpensive analytical technique compared with LC-MS. This analysis can be a useful tool to determine the amount of FQ discharged from WWTPs into the aquatic environment and evaluate the effect of the treatment in their elimination. Our results show reduction of the concentrations of the antibiotics in the range 53 to $92 \%$. This correlates with studies from other countries and showed that elimination during treatment process in not complete and it is necessary to improve treatment processes and to prevent entrance of antibiotics into the aquatic environment and their persistence there.

The relatively high concentrations of antibiotics found in this work, ranging from 100.8 to $10,962.5 \mathrm{ng} \mathrm{L}^{-1}$ for CIPRO, from 353.3 to $10,675.5 \mathrm{ng} \mathrm{L}^{-1}$ for OFLO, and from 29.6 to $455.0 \mathrm{ng} \mathrm{L}^{-1}$ for NOR, support the statement that hospitals are primary and very important contributors of antibiotics to municipal wastewaters, and underscore the importance of development of local and nationwide surveys of antibiotics in Portugal.

Acknowledgments Marcela Seifrtová and Petr Solich are funded by Research Project MSM 0021620822.

\section{References}

1. Hartig CT, Storm M, Jekel M (1999) J Chromatogr A 854:163-173

2. Hartmann A, Alder AC, Koller T, Widmer RM (1998) Environ Toxicol Chem 17:377-382

3. Hirsch R, Ternes T, Haberer K, Kratz KL (1999) Sci Total Environ 225:109-118

4. Díaz-Cruz MS, Barceló D (2007) Anal Bioanal Chem 386:973-985

5. Brown KD, Kulis J, Thomson B, Chapman TH, Mawhinney DB (2006) Sci Total Environ 366:772-783

6. Morris AK, Masterton RG (2002) J Antimicrob Chemother 49:7-10

7. Lindberg R, Jarnheimer PA, Olsen B, Johansson M, Tysklind M (2004) Chemosphere 57:1479-1488

8. Kümmerer K, Henninger A (2003) Clin Microbiol Inf 9:1203-1214

9. Golet EM, Alder AC, Giger W (2002) Environ Sci Technol $36: 3645-3651$ 
10. Karthikeyan KG, Meyer MT (2006) Sci Total Environ 361:196-207

11. Nakata H, Kannan K, Jones PD, Giesy JP (2005) Chemosphere 58:759-766

12. Golet EM, Alder AC, Hartmann A, Ternes TA, Giger W (2001) Anal Chem 73:3632-3638

13. Turiel E, Bordin G, Rodríguez AR (2003) J Chromatogr A 1008:145-155

14. Reverté S, Borrull F, Pocurull E, Marcé RM (2003) J Chromatogr A 1010:225-232

15. Lindberg RH, Wennberg P, Johansson MI, Tysklind M, Andersson BAV (2005) Environ Sci Technol 39:3421-3429

16. Pena A, Chmielová D, Lino CM, Solich P (2007) J Sep Sci 30:2924-2928

17. Forlay-Frick P, Fekete J (2004) J Liq Chromatogr Related Technol 27:123-143
18. Park HR, Kim TH, Bark KM (2002) Eur J Med Chem 37:443460

19. Lee HB, Peart TE, Svoboda ML (2007) J Chromatogr A 1139: $45-52$

20. Turiel E, Bordin G, Rodríguez AR (2005) J Sep Sci 28:257-267

21. Kim SC, Carlson K (2007) Anal Bioanal Chem 387:1301-1315

22. Renew JE, Huang CH (2004) J Chromatogr A 1042:113-121

23. Jacobsen AM, Halling-Sorensen B, Ingerslev F, Hansen $\mathrm{SH}$ (2004) J Chromatogr A 1038:157-170

24. Pena A, Lino CM, Silveira MIN (2003) JAOAC Int 86:925-929

25. Miao XS, Bishay F, Chen M, Metcalfe CD (2004) Environ Sci Technol 38:3533-3541

26. Picó Y, Andreu V (2007) Anal Bioanal Chem 387:1287-1299

27. Golet EM, Xifra I, Siegrist H, Alder AC, Giger W (2003) Environ Sci Technol 37:3243-3249 